\title{
El carnaval de invierno de Punta Arenas. Esbozo de una festividad desde una perspectiva antropológica
}

\author{
The Winter Carnival of Punta Arenas \\ Outline from an anthropological perspective \\ José TONKO P. \\ "Trabajador Social, Investigador Fundación para el Desarrollo de Magallanes, FIDE XII \\ josetonko@yahoo.com
}

\begin{abstract}
RESUMEN
El Carnaval de invierno es una festividad popular en la ciudad de Punta Arenas y su importancia radica en su carácter único comparado con otros carnavales del mundo. En este trabajo se describe el carnaval desde un punto de vista antropológico, observándolo como performance, con lo cual nos aproximamos a las múltiples significaciones y modos de organización que tiene la festividad, así como a los actores que participan en él.
\end{abstract}

Palabras clave: Carnaval, Invernadas de Punta Arenas, Performance, Símbolos.

\begin{abstract}
The Winter Carnival is a popular festival in the city of Punta Arenas and its importance lies in its uniqueness compared to other carnivals in the world. In this work we will focus on the carnival from an anthropological point of view, observing it as a performance, with which we will try to approach the multiple meanings and modes of organization that has the festival, as well as the actors who participate in it.
\end{abstract}

Key words: Carnival, Punta Arenas's Wintering, Performance, Symbols.

La interpretación de la cultura consiste en buscar estructuras significativas que permitan el destilado de sentido y significado; en conjeturar significaciones y estimar las "mejores" conjeturas para llegar a unas conclusiones interpretativas. Estas conclusiones tienen que ofrecer significados que permitan dar significados a 
las tramas (textos) que conforman la cultura donde está inserto el individuo.

El carnaval de Santa Cruz de Tenerife: Un estudio antropológico. Barreto

\section{INTRODUCCIÓN}

Este trabajo se configura como una aproximación epistemológica al fenómeno del carnaval concebido como "evento performativo" (Turner, 1986). Complementariamente, se plantean algunas interrogantes a la noción de cultura implicada en esta perspectiva analítica. Turner (1986) estudia los eventos performativos en el sentido de eventos humanos, más específicamente rituales sociales en los que se encuentra la vida cotidiana, como los deportes y fiestas populares, entre otros fenómenos. Este autor visualiza estas prácticas sociales enmarcadas en una noción de cultura como un proceso o una serie de "actuaciones" (performances). Dentro de estas actuaciones se encuentra el carnaval, que se puede concebir como una puesta en escena, al igual que una obra de teatro donde hay actores y espectadores que interactúan. Por otro lado, debemos citar a Geertz (1996) respecto a cómo concibe la descripción antropológica: “...los escritos antropológicos son ellos mismos interpretaciones y por añadidura interpretaciones de segundo y tercer orden”, (Geertz , 1996, p. 21).

Bajo estas dos perspectivas, intentaremos obtener una "descripción densa" (en el sentido geertziano) del Carnaval de Invierno de Punta Arenas, considerando dos aspectos centrales en su observación:

a) El escenario y sus características singulares (por ejemplo, "abierto" por no estar circunscrito a un espacio cerrado; "móvil" por la movilidad de los actores; "libre" o "accesible" por el hecho de que todo el mundo puede participar).

b) A los actores, quienes participan en la festividad (participantes activos y pasivos: el público), donde se realizan diversas actuaciones y rituales (elección de reina, desfile de la reina, etc.). Entre las actuaciones se puede señalar la asunción de roles por parte de los actores, por ejemplo, de los que participan en diversos carros alegóricos temáticos, con "gauchos", "indígenas", “colonos croatas", “colonos chilotes”, etc.

En consecuencia al describir desde nuestra propia visión el carnaval de invierno de Punta Arenas y posteriormente interpretarlo desde un punto de vista antropológico, se es fiel a la perspectiva etnográfica en los estudios culturales y específicamente a la consideración metodológica de Geertz (1996) precitada.

El Carnaval de invierno de Punta Arenas es un evento en el cual confluyen diferentes modalidades del actuar, percibir y construir. Se singulariza por ser una festividad que ocurre en una fecha diferente a las de otros carnavales en el mundo que se celebran antes del 
comienzo de la cuaresma cristiana, entre febrero y marzo. Sin embargo, no es el único carnaval de invierno, puesto que celebraciones como esta ocurren igualmente en otras localidades. Un punto de singularidad podría ser que se trata del carnaval más austral del continente americano y, por otra parte, no sigue los patrones usuales de desenfreno y liberalidad de otras latitudes, ya que es una celebración que podríamos llamarla "familiar".

Desde un punto de vista histórico, los carnavales se remontan a tiempos muy antiguos de la historia de la humanidad, según se puede apreciar en la literatura. Abarca desde la antigua Sumeria, hace cerca de 5.000 años, hasta el presente. Sus formas, ciertamente han variado con el tiempo y, de ser una fiesta pagana, posteriormente tuvo su conexión con el cristianismo en lo que respecta a la fecha de su celebración y el sentido de tal celebración. El carnaval se celebra antes del comienzo de la cuaresma cristiana, entre febrero y marzo. El sentido religioso está inserto en la misma palabra, de origen latino carne-vale (adiós a la carne), que alude a la prohibición de comer carne durante el período de cuaresma. No obstante la iglesia no acepta la celebración como una fiesta religiosa.

Se estima que las primeras celebraciones ocurrieron antes del nacimiento de Cristo; estas celebraciones estaban fuertemente relacionadas con la agricultura. Para este evento los campesinos se reunían en verano con sus cuerpos totalmente pintados y sus rostros completamente enmascarados, se juntaban alrededor de una hoguera, para celebrar la productividad y la fertilidad del suelo, o bien para alejar los malos espíritus de la cosecha.

Posteriormente la celebración del carnaval se expande a Egipto. En esta fiesta los concurrentes bailaban, cantaban y los participantes venían con máscaras y disfrazados como símbolo de la inexistencia de clases sociales.

Después, por el siglo VI a.e.c., esta tradición se extendió a Grecia. Aquí la celebración consistía en pasear en un barco con ruedas (carrus navalis) donde la gente bailaba todo tipo de danzas.

Posteriormente en Roma, se realizaban numerosas fiestas paganas en torno al dios Baco, el dios del vino. Esta celebración servía para dos propósitos: uno, la ceremonia estaba ligada a fenómenos espirituales, astronómicos y otra, tanto los ricos como los pobres se mezclaban en libertad durante el carnaval, sin reconocerse bajo las máscaras y el disfraz.

Después, en tiempos modernos el carnaval se ha expandido a todo el mundo; poco a poco, el carnaval ha ido modificándose e incorporando las costumbre y los hábitos de cada país.

\section{EL CARNAVAL DE INVIERNO EN PUNTA ARENAS}

El carnaval de invierno en Punta Arenas es una de las fiestas de mayor afluencia de público; aquí gran parte de los habitantes concurren a la Avenida Bories a presenciar los desfiles de carros, murgas y batucadas. El recorrido del carnaval se da de norte a sur, siendo el punto de inicio la calle Pedro Sarmiento de Gamboa. A lo largo de esta calle la gente ávida 
de espectáculo se posiciona para contemplar la puesta en marcha de este magno espectáculo para la región.

En el espacio público donde se registra el desfile hay tránsito de todo tipo. De repente hay cosas imprevistas y cosas paradógicas. En este espacio hay una movilidad constante y de paso; las relaciones sociales que se dan aquí en la calle no están jerarquizadas, son libres y espontáneas; no obstante, existen pautas de conducta sociales que deben ser cumplidas. El espacio público de uso masivo cuando no está ocupado por el carnaval está dividido en tres partes y cada una de ellas cumple un rol específico:

a) La plaza es donde algunas personas vienen a descansar, otras andan de paso y los niños ocupan el espacio para jugar. Asimismo es punto obligatorio de visita de turistas.

b) La vereda es de uso múltiple: en algunos momentos es un punto de carga y descarga de mercancías de los locales comerciales; no obstante, su función principal es de libre uso de transito peatonal.

c) La calle en tiempos modernos solo está destinada al tránsito de los autos particulares y vehículos de locomoción colectiva.

Este espacio público cambia de función cuando, al inicio del invierno, se da inicio al carnaval. En estos espacios de uso múltiple y de uso restringido ocurre una gran metamorfosis: el espacio de uso vehicular se transforma en un gran escenario en donde se montan varias obras. Este espacio está abierto a todo el mundo, aparte de los que realizan la performance, a la representación montada en los carros alegóricos y al paso de pequeñas agrupaciones de personas que desfilan, las cuales pueden clasificarse en varios tipos: (1) personas pertenecientes a distintas agrupaciones (clubes, colegios, jardines infantiles, reparticiones públicas y privadas; descendientes de inmigrantes, etc.), que preceden o siguen a un carro alegórico, con los cuales forman un conglomerado con una pertenencia grupal definida; (2) personas similares a (1), pero sin un carro alegórico, identificadas en ocasiones por abanderados y porta-estandartes identificatorios; (3) grupos de danzantes o miembros de batucadas que portan tambores y otros instrumentos de percusión.

En este espacio, la calle, se dan cita y se junta la gente para ver transitar los carros alegóricos y los danzantes. La vereda se transforma en galería y allí hay una gran multitud de personas tratando de buscar el mejor lugar para observar y deleitarse con el paso del carnaval. En este nuevo orden de la estructuración del espacio público se rompe la barrera del espacio proxémico, ya que hay un nueva configuración espacial.

La realidad cotidiana de las personas se ve interrumpida por el desfile, y cada una se convierte en participante activo en esta representación, adquiriendo el rol de espectadores no enteramente pasivos, ya que como espectadores pueden aplaudir, gritar y abuchear a los que desfilan. Asimismo pueden ocasionalmente sumarse al desfile o participar en algún baile, como miembros activos del desfile. El espectador no está confinado a su rol de espectador, 
sino que es un ente que en cualquier momento puede convertirse en un miembro más de los actores de la performance. La calle es un escenario en movimiento, lleno de colorido y sonido.

\section{CARROS ALEGÓRICOS Y COMPARSAS COREOGRÁFICAS}

Los visitantes son bienvenidos a participar del festejo, ya que se trata de una celebración mesurada y tranquila. El desfile es una ventana que invita a observar la arquitectura de los objetos icónicos en tránsito, cada uno con formas y estructuras únicas y diferenciadas; sobre sus cubiertas están los sujetos participantes con disfraces de colores y formas múltiples.

En el desarrollo de la escena hay desfiles de carros alegóricos con variados tipos, formas y motivos; en cada uno de los carros hay música y en cada tarima están los participantes actuando dando una forma, un significado, un contenido especial al carro en cuestión.

Los carros alegóricos podemos concebirlos como escenarios donde se representa una "obra teatral". Por ejemplo, el carro que representa una escena campestre donde un grupo de gauchos prepara un asado, en un ambiente festivo y con elementos reales. La carne que se asa es real, los elementos exhibidos: herramientas, útiles de cocina y otros que forman parte de una escena de estancia y que aparecen para "otorgarle atmósfera" al carro, también son reales y forman parte de la cultura material de ese mundo gauchesco que se pretende representar. Los actores de esta escena aparecen igualmente ataviados con la vestimenta típica y forman un cuadro que se exhibe ante los espectadores. Cada carro es una puesta en escena diferente, donde se representa una "pieza teatral" para los espectadores. Los carros se distinguen porque en su mayoría corresponden a retratos que tienen que ver con la realidad regional -como el de los "gauchos"- pero los hay también aquellos que representan a establecimientos educacionales, pueblos originarios de la región y acontecimientos históricos, como la llegada de los colonos, industrias y comercio de la región.

Aparte de estos carros, hay otro que reviste importancia y es aquel donde va la reina del carnaval, cuyo proceso de elección forma parte de las actividades previas al desfile. De este modo, se combinan carros de "mundos reales" y "mundos de fantasía", los cuales compiten por obtener el premio del mejor carro. Las autoridades se sitúan en la plaza principal de la ciudad por donde pasan los carros y otros participantes del desfile.

Uno de los elementos que se explota en nuestra región es el de las comparsas, que son grupos de música y baile que escogen un tema tradicionalmente festivo o alegórico que aluden a cosas típicas del país. Los integrantes de las comparsas se preparan durante meses ensayando su número, coordinado y sincronizando todos sus movimientos con la música. En la presentación oficial, los participantes se visten de llamativos atuendos de colores múltiples. Con esta parafernalia dan vida a los animados desfiles del carnaval de invierno, donde se premian a los grupos o comparsas mejor preparados y con movimientos más sincronizados. 


\section{AL RITMO DE LA SALSA Y BATUCADA}

El carnaval de Punta Arenas obviamente es una actividad de carácter temporal y breve, por lo tanto todas las interacciones y rituales se dan en un espacio y tiempo concretos. La música, el baile y el disfraz forman parte del entramado del carnaval y son elementos esenciales que le dan vida y colorido al evento. Por esta misma razón, las batucadas no podrían estar ausentes ya que forman parte de la obra. Sus integrantes no sobrepasan las 25 personas, de las cuales algunas van con sus tambores e instrumentos de percusión al cinto, imprimiéndole un ritmo especial al evento.

Los asistentes viven un momento fugaz de alegría y entretención, mientras que los participantes andan con un vestuario llamativo y cuando pasan por la calle principal del circuito realizan una coreografía espectacular. Aquí la música y el baile se entremezclan y los “actores" participantes, haciendo alusión a su coreografía, le dan un sentido y cierto significado a la puesta en escena de su obra. En cada obra hay un tipo de comunicación, ésta pueden ser implícita o explícita. En el caso de las batucadas la comunicación es implícita, la música y el baile hablan de ellos mismos, de lo que quieren expresar.

En esta frágil unión los grupos y los participantes no nos quieren expresar los conflictos que suceden en el barrio o en la sociedad, esos conflictos o problemas se dejan de lado, sabiendo que tienen intereses contrapuestos, pero en este frágil momento existe una conciencia de grupo: lo que quieren demostrar al mundo es la unión solidaria. En este instante de unión efímera todos los integrantes están dispuestos a adquirir prestigio social, ya que al ganar en la categoría en la cual participan serán reconocidos por las autoridades de la región y la ciudadanía. No obstante, este prestigio social tiene corta duración y después del término del carnaval todo pasa al olvido. Sobre esta idea, se puede citar a Barreto (1993) quien aporta reflexiones de su estudio sobre el carnaval de Tenerife, en España:

El baile, la risa, los gestos y la pintura ayudan a pasar el carnaval. Prometen la plenitud de las fiestas que se celebran bajo la amenaza de lo efímero, del miedo a llegar al final, de agotar por completo el cuerpo. El carnaval permite momentos de locura, de excesos, de libertad. Es una manera de hacer descansar al cuerpo de su formalidad y monotonía habituales. Un aspecto importante de la fiesta es así, el encuentro del cuerpo con la naturaleza (Barreto 1993, p. 435).

\section{SENTIDO “OCULTO” DE LA PERFORMANCE}

La presentación de la obra en términos genéricos se ve como amorfa, sin sentido, pero todas las representaciones tienen un sentido abstracto. Haciendo una lectura de los mensajes que se encuentran ocultos en cada una de las figuras podemos deducir que toda la obra puesta en marcha tiene un significado. Todas las figuras icónicas aluden a la identidad 
y a la pertenencia a un determinado lugar, resaltando los valores idiosincráticos de sus habitantes en las figuras de pioneros esforzados, mineros, inmigrantes, pueblos originarios desaparecidos y por desaparecer.

En el carnaval hay una interacción social, los individuos no están aislados sino que comparten con otros. Las actividades y la performance del carnaval son actividades públicas de representaciones. En cada una de estas actividades, los participantes asumen un rol activo en la puesta en escena de su obra, por tanto sus actos y comportamientos están directamente asociados a la performance.

Los actores no escapan de la visión del espectador. Un carro alegórico que pasa frente a los espectadores no es cualquier carro, ya que durante la construcción de éstos se quiere expresar un determinado motivo y ese motivo está reflejado en la estructura, en el conglomerado y en el objeto en cuestión. Por ello, cada uno de los individuos que participan asumen un rol determinado para hacer posible esa lectura por parte del público espectador. En la escenificación (ya que un carro es un escenario) los actores asumen un personaje y deberán actuar acorde a tal personaje. Los actores deberán coordinarse para entregar un mensaje completo de lo que están representando.

\section{EL USO DE LOS SÍMBOLOS}

¿Cuál es el significado simbólico de los carros y figuras? y ¿A qué cosas aluden? De los símbolos se pueden inferir las relaciones económicas, políticas y estéticas. El significado de los carros alegóricos es muy variado, podemos encontrar carros con diferentes motivos que pueden obedecer a las figuras que se encuentran en boga en ese momento. Por ejemplo, en el caso de la empresa nacional Sodimac -instalada en Punta Arenas- una vez elaboró un carro que presentaba una figura principal que era "Bob el constructor".

Aquí el mensaje es claro; en primer lugar, con la figura del maestro constructor se alude a que en esa empresa hay elementos para la construcción y en segundo lugar, nos está indicando que en esa empresa hay expertos en la materia. Los que representan a los pueblos originarios quieren expresar la presencia dentro de una ausencia. Los pueblos originarios, extintos o casi extintos, forman parte del patrimonio regional, pero son reconocidos como patrimonio en una función icónica. Las culturas emergen ante el espectador como conjuntos de significados fosilizados en una representación casi fotográfica, ya que aparecen en el carro-escenario en forma estática, dado que los actores no conocen las prácticas culturales de estos pueblos cuando estuvieron vivos, no hay testimonios de las ceremonias o rituales que existieron y al no conocerlos o no estudiar profundamente sus registros etnográficos, no pueden recurrir a un imaginario desde la perspectiva del "otro" cultural. Pero como es una representación, la puesta en escena y la actuación misma carecen de importancia o relevancia y lo que vale es la representación, entendida como la presencia de estos pueblos en el desfile, puesta allí por la necesidad de mostrar que estas comunidades pertenecen a la región, y 
según esta pertenencia, “deben” estar allí. Es una muestra de un pasado remoto, no conocido, que no se quiere que caiga más al olvido de lo que está.

\section{ORGANIZACIÓN ESTRUCTURAL DEL CARNAVAL}

El carnaval, obviamente, no surge espontáneamente, sino que hay toda una preparación previa por parte de los intervinientes, los sujetos actuantes de la performance. Esta preparación está a cargo de organizaciones específicas tales como empresas, agrupaciones vecinales, organizaciones indígenas, miembros de los diferentes estamentos educacionales (colegios, institutos y universidades), cuerpos cívicos (bomberos, grupos scouts), etc.

Siguiendo a Turner (1987) las actividades se pueden dar en tres niveles:

a) Nivel de la interpretación, en donde se debe responder a las siguientes preguntas: ¿Están preparados los sujetos para participar? ¿Los sujetos tienen claro lo que van a hacer (pintar decorar, arreglar)?

b) El sentido operacional, que debe responder a estas preguntas: ¿Hay un líder para realizar la actividad? ¿Todos conocen sus tareas? ¿En ciertos tramos los sujetos van a moverse como una sola unidad?

c) El sentido posicional y sus preguntas: ¿Todos los implementos que tiene el grupo, en qué lugar se encuentran emplazados?

El carnaval fomenta la competencia y se visualiza a través de los costosos disfraces y parafernalia. En este sentido, tener el mejor y más original disfraz, será evaluado positivamente por parte de los jueces, generando así en los colectivos que participan una gran satisfacción. Este espíritu de competición que reina en el carnaval satisface los deseos de los participantes y si logran ganar, tendrán un sitio de honor dentro de la sociedad magallánica.

A nivel político gubernamental, mientras mayor sea la participación de todos los actores sociales e instituciones, para el gobierno regional será un logro avanzado y además genera prestigio hacia el exterior. Bajo esta lógica es un espectáculo que se hace vender y por ello generará divisas importantes para la región. Por otro lado, la fiesta de carnaval es una fiesta de carácter regional, su intención es que los habitantes compartan y tengan la satisfacción de haber experimentado junto a sus coterráneos a un evento de carácter regional. Además, en los días que se presenta el carnaval se genera una gran efervescencia de público que insta a la participación y al consumo.

Aparte de estos rasgos y volviendo a los actores de la performance, es necesario consignar que el vestuario de los participantes, los disfraces, a menudo son representaciones contrastantes con la realidad personal. Los disfraces elaborados que representan a personajes poderosos (reyes, reinas, princesas, etc.), contrastan con la pertenencia social que puede tener quien los viste: La oposición rico-pobre, por ejemplo. Además, hay otras 
oposiciones que se pueden apreciar, como por ejemplo, participantes femeninas con vestimenta muy ligera, inapropiada para el clima y que se ve más bien en carnavales de otras latitudes y de clima cálido. En sí no es una oposición que refleje la diferencia de cálido-frío, sino más bien la resistencia al frío a pesar de la semi-desnudez. La presencia de actores que representan el origen inmigrante de parte de la población regional (croatas, ingleses, españoles), vestidos con trajes típicos, muestra las oposiciones origen europeoorigen autóctono, en donde los últimos incluyen a chilotes, descendientes de pueblos originarios y chilenos de otros puntos del país.

La motivación del disfraz conlleva, de esta manera, a una cierta valorización en donde hay una jerarquización de valor más y menos alto dependiendo de la pertenencia del origen. Por lo general, es de valoración más alta la de “origen europeo”, pero también la de "origen chilote", que se valora más alto que la de "pueblo originario" y la de "origen mapuche”, que a su vez se valora más alto que la "de origen fueguino” (kawésqar, yagán, selk'nam), ya que algunas personas de origen mapuche enfatizan su expansión territorial al ser también “colonos” de esta región tan apartada de su territorio de origen.

El carnaval de invierno, entonces, resalta la identidad como un elemento de identificación o pertenencia a una región o grupos étnicos. A través de la puesta en escena de todos los elementos icónicos se apela a la conciencia de la identidad como grupo. Al ritualizar la pertinencia desde lo intra-grupal, se intentan conservar las diferencias (por ejemplo, a través de los distintos carros como el de la Armada, de los inmigrantes, etc.), pero el llamado de fondo es la homogeneización a través del mensaje como pioneros y como gente de esfuerzo, además de apelar fuertemente a la valorización regional frente a un gobierno centralista que muchas veces no presta suficiente atención a estos habitantes de un territorio tan extremo. Por ello, el carnaval se presenta como una máquina perfecta para exaltar los valores idiosincráticos de la región. La pertenencia al territorio hace igualmente que la figura o el carro más representativo que aluda a la región, quede archivado en la memoria colectiva de un pueblo como referente simbólico importante o significativo.

Como se dijo más arriba, los espectadores participan de manera tranquila de la festividad, a la que concurren familias completas a ver -y en cierta medida- a participar mesuradamente a través de aplausos o gritos al paso de los carros y de los otros participantes del desfile. No hay catarsis colectiva, no hay caos, ni tampoco un quiebre del orden establecido, solo hay contemplación para los ojos de los espectadores y el maravillarse en especial para los más pequeños. Hay un ambiente festivo, alegre, sin importar si el clima se endurece. El carnaval de invierno con una nevazón es más singular aún, ya que es una muestra de la resistencia a la inclemencia climática por parte de los habitantes de una de las ciudades más australes del mundo y de quienes han llegado de localidades vecinas, tanto de Chile como desde la Patagonia argentina a participar de un fiesta comunitaria y ciudadana. 


\section{CONCLUSIONES}

La descripciones e interpretaciones presentadas del Carnaval de Invierno de Punta Arenas parten de la concepción de una observación donde nos ubicamos como sujetos externos, ya que contemplamos una realidad constituida por una festividad en la que hay actores que observamos y cuya actuación describimos, pero al mismo tiempo interpretamos lo que nos quieren decir a través de estas actuaciones. La performance, con sus representaciones en el sentido de re-presentarse (al presentarse como otro) y al asumir roles de entidades, sujetos diferentes nos "cuentan" historias que quieren representar. En cierto sentido, observamos en la performance varias realidades que se superponen y se mezclan, pero por tener un orden lineal no son caóticas. Se superponen en el sentido que aquellos escenarios que narran un mito de origen (el componente europeo de la sociedad magallánica, el chilote, el indígena) son un mismo mito: el origen; se mezclan porque son componentes de una gran representación que es el carnaval, pero temporalmente están separados porque la representación tiene una secuencia, una sucesión de escenarios que pasan delante del espectador.

\section{REFERENCIAS}

Barreto, C. (1993) El carnaval de Santa Cruz de Tenerife: Un estudio antropológico. Tesis doctoral. San Cristóbal de la Laguna: Universidad de la Laguna. Recuperado en: ftp:// tesis.bbtk.ull.es/ccssyhum/cs177.pdf

Geertz, C. (1996). La interpretación de las culturas. Barcelona: Gedisa.

Schutz, A. (1995). El problema de la realidad social. Buenos Aires: Amorrortu.

Turner, V. (1987). The Anthropology of Performance. New York: PAJ Publications. 